\title{
Antenatal Magnesium Sulfate and Preeclampsia Differentially Affect Neonatal Cerebral Oxygenation
}

\author{
Anne E. Richter ${ }^{a}$ Sicco A. Scherjon ${ }^{b}$ Riksta Dikkers ${ }^{c}$ Arend F. Bos ${ }^{a}$ \\ Elisabeth M.W. Kooi ${ }^{\mathrm{a}}$ \\ aDivision of Neonatology, Beatrix Children's Hospital, University Medical Center Groningen, University of \\ Groningen, Groningen, The Netherlands; ${ }^{b}$ Department of Obstetrics and Gynecology, University Medical Center \\ Groningen, University of Groningen, Groningen, The Netherlands; ' ${ }^{\mathrm{D}}$ Department of Radiology, University Medical \\ Center Groningen, University of Groningen, Groningen, The Netherlands
}

\author{
Keywords \\ Magnesium sulfate $\cdot$ Preeclampsia $\cdot$ Fetal brain sparing · \\ Cerebral autoregulation $\cdot$ Cerebral oxygenation $\cdot$ Cerebral \\ blood flow
}

\begin{abstract}
Introduction: Magnesium sulfate $\left(\mathrm{MgSO}_{4}\right)$ is frequently administered for maternal and fetal neuroprotection in preeclampsia (PE) and imminent preterm birth, respectively. Objective: To assess whether $\mathrm{MgSO}_{4}$ affects neonatal cerebral oxygenation, blood flow, and cerebral autoregulation (CAR) during the first postnatal days independently from PE. Methods: 148 neonates $<32$ weeks gestational age were included. Cerebral fractional tissue oxygen extraction (cFTOE) was extracted from a daily 2-h period, during which peak systolic blood flow velocity (PSV) and resistance index (RI) of the pericallosal artery were obtained. The percent time of impaired CAR (correlation coefficient between mean arterial blood pressure and cerebral oxygen saturation $>0.5$ ) was determined. Linear mixed models were applied. Results:
\end{abstract}

$\mathrm{MgSO}_{4}$ exposure was recorded in 77 neonates. Twenty-nine neonates were born following $\mathrm{PE}$. $\mathrm{MgSO}_{4}$ independently lowered cFTOE (B: $-0.026,95 \% \mathrm{Cl}:-0.050$ to $0.002, p<0.05$ ) but did not affect PSV and RI. PE was associated with a lower CFTOE (B: $-0.041,95 \% \mathrm{Cl}:-0.067$ to $-0.015, p<0.05)$ and a tendency towards both lower PSV (B: $-4.285,95 \% \mathrm{Cl}$ : -9.067 to $0.497, p<0.1$ ) and more impaired CAR (B: $4.042,95 \% \mathrm{Cl}$ : -0.028 to $8.112, p<0.1$ ), which seemed to be strongly mediated by fetal brain sparing. $\mathrm{MgSO}_{4}$ did not alter CAR. Conclusions: In contrast to fetal brain sparing in $\mathrm{PE}, \mathrm{MgSO}_{4}$ seems to lower CFTOE by lowering cerebral oxygen demands in preterm neonates without affecting the cerebrovasculature.

(c) 2020 The Author(s)

Published by S. Karger AG, Basel

\section{Introduction}

$\mathrm{MgSO}_{4}$ is used to prevent maternal seizures in preeclampsia (PE) and protect the fetal brain in preterm delivery $[1,2]$. Although $\mathrm{MgSO}_{4}$ reduces the risk of neonatal
(C) 2020 The Author(s)

Published by S. Karger AG, Basel

This article is licensed under the Creative Commons AttributionNonCommercial-NoDerivatives 4.0 International License (CC BYNC-ND) (http://www.karger.com/Services/OpenAccessLicense). Usage and distribution for commercial purposes as well as any distribution of modified material requires written permission.
Anne Elisabeth Richter

Division of Neonatology, Beatrix Children's Hospital University Medical Center Groningen, University of Groningen Hanzeplein 1, NL-9713 GZ Groningen (The Netherlands) a.e.richter@umcg.nl 
cerebral palsy, its benefits concerning periventricular leukomalacia (PVL), intraventricular hemorrhage (IVH), and mortality remain controversial [3]. Moreover, its neuroprotective mechanisms are poorly understood, but have mainly been attributed to a reduction in hypoxiaand inflammation-induced glutamate excitotoxicity by NMDA receptor blockade $[4,5]$. In addition, the calcium entry-blocking properties of magnesium make it a potent smooth muscle relaxant [5].

We previously reported that antenatal $\mathrm{MgSO}_{4}$ is associated with a lower neonatal cerebral fractional tissue oxygen extraction (cFTOE), either due to reduced cerebral oxygen consumption associated with lower cerebral metabolism or increased cerebral oxygen supply through vasodilatory mechanisms [6]. Although $\mathrm{MgSO}_{4}$ has been reported to affect cerebral blood flow (CBF), a confounding effect of maternal PE can frequently not be excluded [7-9]. Likewise, fetal brain sparing (preferential cerebral perfusion in response to placental insufficiency) may have influenced these findings $[6,10]$.

Given the frequent administration of $\mathrm{MgSO}_{4}$ and the uncertainties regarding its hemodynamic effects on the neonatal brain, which may be confounded by underlying maternal $\mathrm{PE}$, we aimed to explore the separate effects of both $\mathrm{MgSO}_{4}$ and $\mathrm{PE}$ on the neonatal cFTOE, CBF, and cerebral autoregulation (CAR) during the first days following preterm birth.

\section{Materials and Methods}

\section{Study Design}

This was a retrospective observational study based on fetal and neonatal measurements performed within the scope of routine clinical care at the obstetric department and the neonatal intensive care unit of the University Medical Center Groningen between June 2016 and June 2018. The study was approved by the institutional ethics committee. Inclusion criteria were gestational age (GA) $<32$ weeks and simultaneous good-quality cerebral oxygenation and blood flow measurements. Exclusion criteria were major cardiac or chromosomal abnormalities, IVH of grade 3 or higher as it can affect cerebral oxygenation, maternal hypertension without $\mathrm{PE}$, and infrequent maternal medication with potential effect on fetal hemodynamics, such as sildenafil, ketanserin, or indomethacin.

\section{$C B F$ and Oxygenation Indices}

Regional cerebral tissue oxygen saturation $\left(\mathrm{r}_{\mathrm{c}} \mathrm{SO}_{2}\right)$ was routinely measured during the first 5 days after birth with near-infrared spectroscopy using an INVOS device (Medtronic, Dublin, Ireland). The corresponding neonatal sensor was placed on either frontoparietal side of the infant's head. Simultaneously, we monitored transcutaneous arterial oxygen saturation $\left(\mathrm{SaO}_{2}\right)$ to calculate cFTOE:
$\mathrm{cFTOE}=\left(\mathrm{SaO}_{2}-\mathrm{r}_{\mathrm{c}} \mathrm{SO}_{2}\right) / \mathrm{SaO}_{2}$

Correlation between $\mathrm{r}_{\mathrm{c}} \mathrm{SO}_{2}$ and invasively measured mean arterial blood pressure (MABP) was assessed for moving windows of 10 -min epochs with $95 \%$ overlap. We determined the percentage of time that the correlation coefficient was $>0.5$, indicating pressure-passive cerebral oxygenation and thus impaired CAR [11]. All data were retrieved at $0.2 \mathrm{~Hz}$. One hour of good quality measurements within a 2 -h period around cranial ultrasound was sufficient for inclusion. Artifacts were manually removed in cases of sensor misplacement, indicated by nonphysiological changes in saturation ( $>20 \%$ change between 2 consecutive data points) or missing physiological variance (flat line). No imputation was performed for missing values.

$\mathrm{CBF}$ was routinely assessed once or twice during the first days after birth, but only once per day, by an experienced pediatric radiologist using Doppler ultrasound. Peak systolic blood flow velocity (PSV) and end-diastolic blood flow velocity (EDV) were measured in the pericallosal artery, as the axis of this artery is closely in line with the angle of insonation, yielding high reproducibility [12]. The resistance index (RI) was calculated as

$$
\mathrm{RI}=(\mathrm{PSV}-\mathrm{EDV}) / \mathrm{PSV} .
$$

\section{Clinical Data Collection}

Mothers were treated with $\mathrm{MgSO}_{4}$ for fetal neuroprotection in case of imminent preterm birth $<30$ weeks GA and/or for the prevention of seizures in $\mathrm{PE}$. Either regimen included an initial intravenous 4-g bolus with a maintenance dose of $1 \mathrm{~g} / \mathrm{h}$. If $\mathrm{MgSO}_{4}$ treatment was stopped at least $24 \mathrm{~h}$ before birth, this was registered as "no exposure" due to its rapid clearance in pregnant women [13]. Antenatal steroids ( $\geq 24 \mathrm{~h}$ before birth) and other maternal medications were recorded.

$\mathrm{PE}$ was diagnosed as pregnancy-induced hypertension with proteinuria (a protein/creatinine ratio $\geq 0.3 \mathrm{~g} / 10 \mathrm{mmol}$ or $0.3 \mathrm{~g}$ in 24 -h urine). The presence of fetal growth restriction was recorded, defined as an abdominal circumference or estimated fetal weight below the 10th percentile. Fetal brain sparing was defined as a cerebroplacental ratio $\bigotimes 1$ at the last prenatal ultrasound, calculated by dividing the pulsatility index of the middle cerebral artery by that of the umbilical artery [14]. If no cerebroplacental ratio was measured due to normal umbilical flow (pulsatility index below the 95th percentile) or normal growth, this was registered as no brain sparing.

\section{Statistical Analysis}

A sample size calculation (supplemental material) was carried out a priori. SPSS 24.0 (IBM Corporation, Armonk, NY, USA) and GraphPad Prism 8.1.2 (GraphPad Software, San Diego, CA, USA) were used. A two-tailed $p$ value $<0.05$ was considered significant. Depending on normality, population characteristics are presented as medians (interquartile ranges) or means $\pm \mathrm{SD}$, tested with the Mann-Whitney U or Student's $t$ test, respectively. Physiologic parameters per day are presented as means \pm SD regardless of normality for easier comparability.

First, we explored (per postnatal day) the correlation between $\mathrm{cFTOE} / \mathrm{r}_{\mathrm{c}} \mathrm{SO}_{2}$ and $\mathrm{CBF}$ parameters using Pearson or Spearman rank correlation for infants exposed or unexposed to $\mathrm{MgSO}_{4}$. Second, the same was done for infants born following PE and non-PE pregnancy. 
Table 1. Descriptive characteristics for infants with and without antenatal $\mathrm{MgSO}_{4}$

\begin{tabular}{|c|c|c|}
\hline & $\begin{array}{l}\text { No antenatal } \mathrm{MgSO}_{4} \\
(n=71)\end{array}$ & $\begin{array}{l}\text { Antenatal } \mathrm{MgSO}_{4} \\
(n=77)\end{array}$ \\
\hline \multicolumn{3}{|l|}{ Gestational characteristics } \\
\hline Preeclampsia & $6(9)$ & $23(30)^{* *}$ \\
\hline Fetal growth restriction & $15(21)$ & $20(26)$ \\
\hline Fetal brain sparing & $7(10)$ & $11(15)$ \\
\hline Antenatal steroids & $31(44)$ & $54(70)^{* *}$ \\
\hline Antenatal labetalol & $4(6)$ & $20(26)^{* *}$ \\
\hline Antenatal methyldopa & $0(0)$ & $8(10)^{* *}$ \\
\hline Antenatal nifedipine & $14(20)$ & $30(39)$ \\
\hline PPROM & $16(23)$ & $13(17)$ \\
\hline Cesarean section & $30(42)$ & $32(42)$ \\
\hline \multicolumn{3}{|l|}{ Neonatal characteristics } \\
\hline Female & $34(48)$ & $30(39)$ \\
\hline Gestational age, weeks & $30.3[29.4-31.3]$ & $28.6[26.9-29.5]^{* *}$ \\
\hline $\begin{array}{l}\text { Birth weight, } \mathrm{g} \\
z \text {-score }\end{array}$ & $\begin{array}{l}1,421 \pm 368 \\
-0.84 \pm 1.16\end{array}$ & $\begin{array}{l}1,157 \pm 328^{* *} \\
-0.94 \pm 1.38\end{array}$ \\
\hline $\begin{array}{l}\text { Head circumference, } \mathrm{cm} \\
z \text {-score }\end{array}$ & $\begin{array}{r}27.5 \pm 2.46 \\
-0.71 \pm 1.03\end{array}$ & $\begin{array}{c}26.0 \pm 2.4^{* *} \\
-0.71 \pm 1.12\end{array}$ \\
\hline Administration of surfactant & $31(44)$ & $42(55)$ \\
\hline Mechanical ventilation & $37(52)$ & $56(73)^{* *}$ \\
\hline Bronchopulmonary dysplasia & $5(7)$ & $14(18)^{* *}$ \\
\hline hsPDA & $11(16)$ & $23(30)^{* *}$ \\
\hline Inotropic therapy ${ }^{1}$ & $4(6)$ & $1(1)$ \\
\hline Necrotizing enterocolitis & $5(7)$ & $9(12)$ \\
\hline Early-onset sepsis & $6(9)$ & $2(3)$ \\
\hline Late-onset sepsis & $9(13)$ & $31(40)^{* *}$ \\
\hline Transfusion-requiring anemia ${ }^{1}$ & $3(4)$ & $2(3)$ \\
\hline Polycythemia ${ }^{1}$ & $3(4)$ & $4(5)$ \\
\hline IVH $\leq$ grade 2 & $13(18)$ & $26(34)^{* *}$ \\
\hline $\mathrm{PVL} \leq$ grade 2 & $32(45)$ & $47(61)^{*}$ \\
\hline Death before discharge & $4(6)$ & $4(5)$ \\
\hline
\end{tabular}

Data are presented as medians [interquartile ranges], means $\pm \mathrm{SD}$, or absolute numbers (\%) within the respective groups. hsPDA, hemodynamically significant (i.e., treatment-requiring) patent ductus arteriosus; $\mathrm{IVH}$, intraventricular hemorrhage; PPROM, prolonged premature rupture of membranes $(>18 \mathrm{~h})$; $\mathrm{PVL}$, periventricular leukomalacia. ${ }^{*} p<0.1,{ }^{* *} p<0.05$, vs. infants with antenatal $\mathrm{MgSO}_{4}$ exposure.

${ }^{1}$ Within the first 5 days after birth.

Next, separate univariate linear mixed-effect analyses were used to compare repeated measures of cFTOE, CBF, and CAR within the first 5 days after birth between infants with and without $\mathrm{MgSO}_{4}$ exposure with $\mathrm{MgSO}_{4}$ as fixed effects, subjects as random effects, and compound symmetry as covariance structure. Post hoc multiple comparison analyses were used to test for differences in daily predicted means, the $p$ values of which are graphically presented. Again, we secondarily ran the same mixed-effect analyses for infants born following PE and non-PE pregnancy.

Finally, both $\mathrm{MgSO}_{4}$ and $\mathrm{PE}$ were forced into one multivariate mixed-effect model with additional adjustment for confounders, such as fetal brain sparing, as fixed effects. By definition, confounders were associated with either $\mathrm{MgSO}_{4}$ or $\mathrm{PE}(p<0.1)$ and changed the estimate of their association with the outcome vari-

Magnesium Sulfate, Preeclampsia, and Neonatal Cerebral Hemodynamics able by $\geq 10 \%$. In case of high association between confounders, the one with the largest change in estimate was included to reduce multicollinearity. Similarly, confounding variables with a variance inflation factor $>5$ were removed from the analysis if they raised the variance inflation factor of $\mathrm{PE}$ or $\mathrm{MgSO}_{4}>5$.

\section{Results}

\section{Clinical Characteristics of the Study Population}

Within the study period, 148 of 271 infants were eligible for analyses (online suppl. Fig. 1; for all online suppl. 
Table 2. Correlation coefficients (number of analyzed infants) between postnatal cerebral fractional tissue oxygen extraction (FTOE) and blood flow parameters within the first 5 days after birth for infants with and without antenatal $\mathrm{MgSO}_{4}$ exposure (a) and infants born following preeclampsia (PE) and non-PE pregnancy (b)

a Infants with and without antenatal $\mathrm{MgSO}_{4}$-exposure

\begin{tabular}{|c|c|c|c|c|c|c|}
\hline & \multicolumn{3}{|c|}{ Antenatal $\mathrm{MgSO}_{4}$} & \multicolumn{3}{|c|}{ No antenatal $\mathrm{MgSO}_{4}$} \\
\hline & RI & PSV & EDV & RI & PSV & EDV \\
\hline \multicolumn{7}{|l|}{ cFTOE } \\
\hline Day 1 & $-0.098(23)$ & $0.154(23)$ & $0.135(23)$ & $-0.054(20)$ & $0.573(20)^{* *}$ & $0.580(20)^{* *}$ \\
\hline Day 2 & $0.057(31)$ & $-0.009(30)$ & $-0.067(30)$ & $0.000(32)$ & $0.112(31)$ & $-0.017(31)$ \\
\hline Day 3 & $0.381(20)$ & 0.187 (18) & $-0.154(18)$ & $0.079(14)$ & $-0.156(14)$ & $-0.147(14)$ \\
\hline Day 4 & 0.095 (14) & $0.055(14)$ & $-0.108(14)$ & $0.056(12)$ & $0.683(11)^{* *}$ & $0.536(11)^{*}$ \\
\hline Day 5 & $0.104(10)$ & $0.333(10)$ & $0.285(10)$ & $-0.117(9)$ & $0.683(8)^{*}$ & $0.357(8)$ \\
\hline
\end{tabular}

b Infants born following PE and non-PE pregnancy

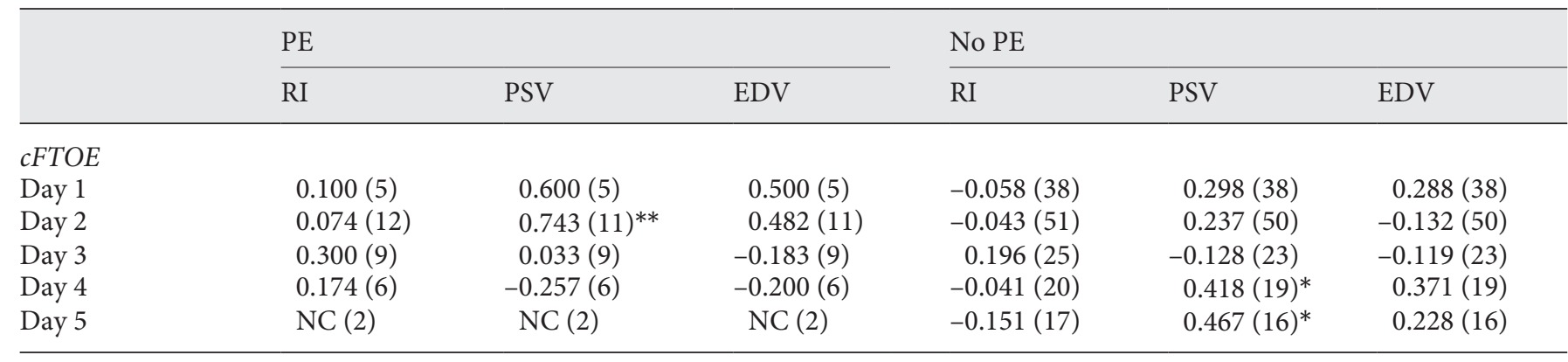

${ }^{*} p<0.1,{ }^{* *} p<0.05$. EDV, end-diastolic velocity; NC, not computable; PSV, peak systolic velocity; RI, resistance index.

Table 3. The association between neonatal hemodynamic parameters during the first 5 days after birth and either $\mathrm{MgSO}_{4}$ or preeclampsia (PE), as analyzed by univariable linear mixed-effect analyses without adjustment for confounders

\begin{tabular}{|c|c|c|c|}
\hline & $\mathrm{B}[95 \% \mathrm{CI}]$ & SE & $p$ \\
\hline \multicolumn{4}{|c|}{ FTOE $(n=148)$} \\
\hline $\mathrm{MgSO}_{4}$ & $-0.020[-0.041$ to 0.000$]$ & 0.010 & $0.055^{*}$ \\
\hline $\mathrm{PE}$ & $-0.041[-0.067$ to -0.015$]$ & 0.013 & $0.002^{* *}$ \\
\hline \multicolumn{4}{|l|}{$\mathrm{RI}(n=148)$} \\
\hline $\mathrm{MgSO}_{4}$ & $0.015[-0.009$ to 0.039$]$ & 0.012 & 0.229 \\
\hline $\mathrm{PE}$ & $-0.010[-0.041$ to 0.020$]$ & 0.015 & 0.506 \\
\hline \multicolumn{4}{|c|}{$\operatorname{PSV}(n=145)$} \\
\hline $\mathrm{MgSO}_{4}$ & $-1.533[-5.360$ to 2.294$]$ & 1.931 & 0.429 \\
\hline $\mathrm{PE}$ & $-4.285[-9.067$ to 0.497$]$ & 2.412 & $0.079 *$ \\
\hline \multicolumn{4}{|c|}{ Impaired CAR, $\%$ time $(n=53)$} \\
\hline $\mathrm{MgSO}_{4}$ & $0.877[-2.152$ to 3.906$]$ & 1.505 & 0.563 \\
\hline $\mathrm{PE}$ & $4.042[-0.028$ to 8.112$]$ & 2.032 & $0.052^{*}$ \\
\hline
\end{tabular}

${ }^{*} p<0.1,{ }^{* *} p<0.05 . \mathrm{B}$, regression coefficient (effect estimate); CAR, cerebral autoregulation; CI, confidence interval; FTOE, fractional tissue oxygen extraction; PSV, peak systolic velocity; RI, resistance index; SE, standard error. material, see www.karger.com/doi/10.1159/000507705). Median GA was 29.4 [28.0-30.4] weeks, and mean birth weight was $1,283 \mathrm{~g}( \pm 371)$. Seventy-seven infants $(52 \%)$ were exposed to $\mathrm{MgSO}_{4}$. These infants were of younger GA and more frequently required ventilation or developed a hemodynamically significant patent ductus arteriosus (hsPDA), mild IVH, late-onset sepsis, and bronchopulmonary dysplasia (Table 1) than infants without $\mathrm{MgSO}_{4}$ exposure. There was also a trend towards more PVL, which was also associated with IVH $(p=0.015)$. IVH itself was associated with younger GA $(p=0.015)$ and a trend towards more hsPDA $(p=0.073)$.

In 54 infants, the indication for $\mathrm{MgSO}_{4}$ was fetal neuroprotection, while in 23 infants it was maternal PE. Median cumulative doses were not different: $10.5 \mathrm{~g}$ (6.4$22.5)$ versus $10.0 \mathrm{~g}(9.0-17.0)$, respectively $(p>0.1)$. In total, 29 infants $(20 \%)$ were born following PE. Compared with infants not born following PE, these infants had smaller birth weight $z$-scores $(-2.28$ vs. $-0.55, p<$ $0.05)$ and were more frequently subjected to antenatal steroids ( 83 vs. $51 \%, p<0.05$ ), brain-sparing ( 52 vs. $3 \%$, 
Fig. 1. The course of fractional tissue oxygen extraction (FTOE) (solid lines), peak systolic velocity (PSV) (dotted lines), and resistance index (RI) (dot-line-dot lines) during the first 5 days after birth for infants with and without $\mathrm{MgSO}_{4}$ exposure (a) and infants born following preeclampsia (PE) and non-PE pregnancy (b). Data are presented as means $( \pm \mathrm{SD}) .{ }^{*} p<0.1,{ }^{* *} p<$ 0.05 .

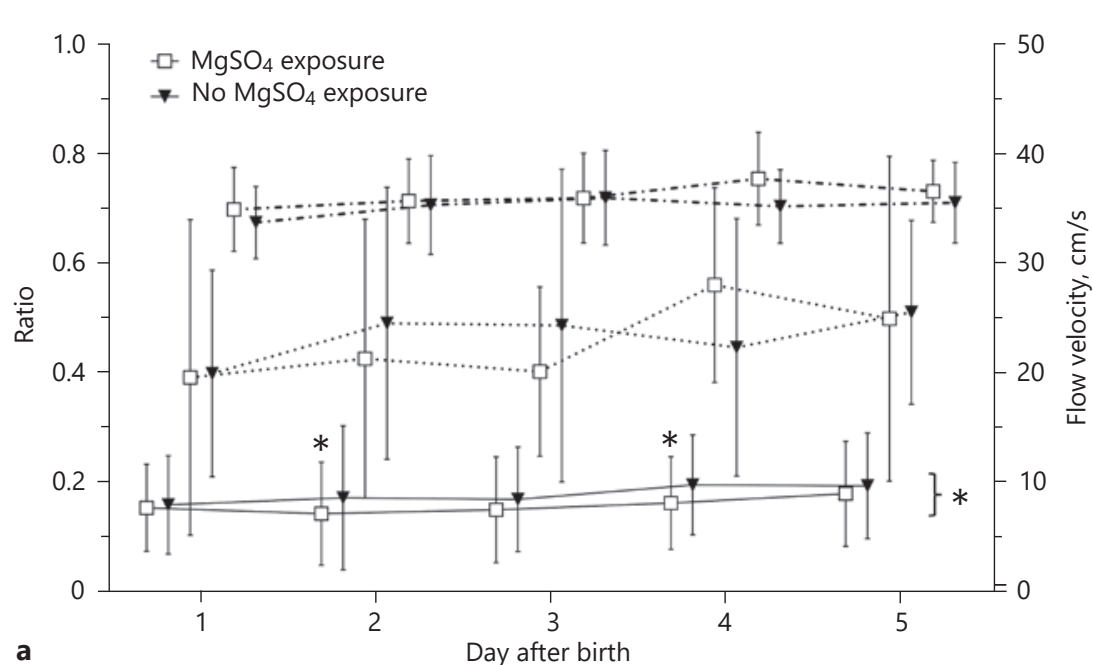

a

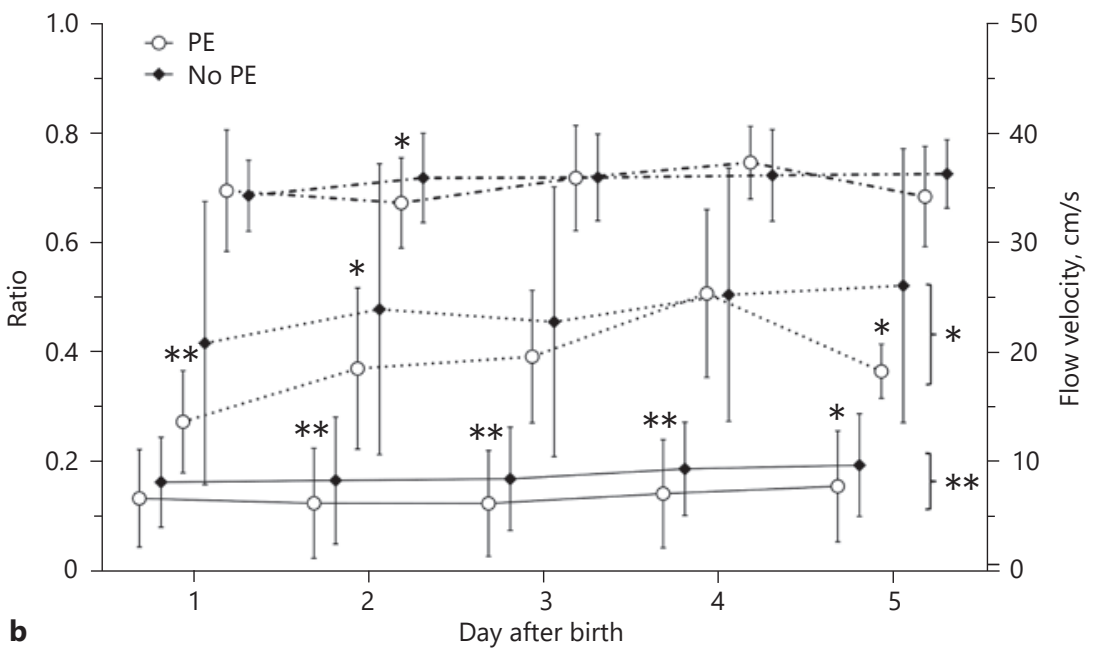

$p<0.05$ ), and $\mathrm{MgSO}_{4}$ (79 vs. $45 \%, p<0.5$ ). Moreover, these infants were exposed to maternal labetalol (83\%) and methyldopa (28\%).

The mean $\mathrm{r}_{\mathrm{c}} \mathrm{SO}_{2}, \mathrm{SaO}_{2}, \mathrm{cFTOE}$, RI, PSV, and duration of impaired CAR within the first 5 days after birth are given in online supplementary Tables 1 and 2 for (a) infants with and without antenatal $\mathrm{MgSO}_{4}$ exposure and (b) infants born following PE and non-PE pregnancy.

\section{Cerebral Oxygenation and Blood Flow}

Only in infants unexposed to $\mathrm{MgSO}_{4}$, cFTOE positively correlated with the pericallosal PSV and EDV on postnatal days 1 and 4 (Table 2). In infants born following PE, cFTOE and PSV positively correlated on postnatal day 2.
There was no correlation between cFTOE and RI. Opposite but similarly significant correlations were seen for $\mathrm{r}_{\mathrm{c}} \mathrm{SO}_{2}$ (online suppl. Table 3).

In univariate linear mixed model analyses, $\mathrm{MgSO}_{4}$ exposure tended to be associated with a lower cFTOE within the first 5 days, particularly on days 2 and 4 (Table 3; Fig. 1), but was not associated with RI or PSV. Maternal PE was associated with significantly lower postnatal cFTOE, which was twice the estimated effect as seen for $\mathrm{MgSO}_{4}$ (Table 3). This was particularly evident on days 2-4 (Fig. 1). Moreover, there was a tendency towards a lower postnatal PSV following PE, which was significant on day 1 after birth. Despite a tendency towards lower RI on day 2 , overall RI was unaffected. 
Fig. 2. The percent time of impaired cerebral autoregulation (\% time per daily $2-\mathrm{h}$ measurement the correlation coefficient between mean arterial blood pressure $[\mathrm{MABP}]$ and regional cerebral oxygen saturation $\left[\mathrm{r}_{\mathrm{c}} \mathrm{SO}_{2}\right]$ was $>0.5$ ) during the first 5 days after birth for infants with and without $\mathrm{MgSO}_{4}$ exposure (a) and infants born following preeclampsia (PE) and non-PE pregnancy (b). Data are presented as means $( \pm \mathrm{SD}) .{ }^{*} p<0.1$.

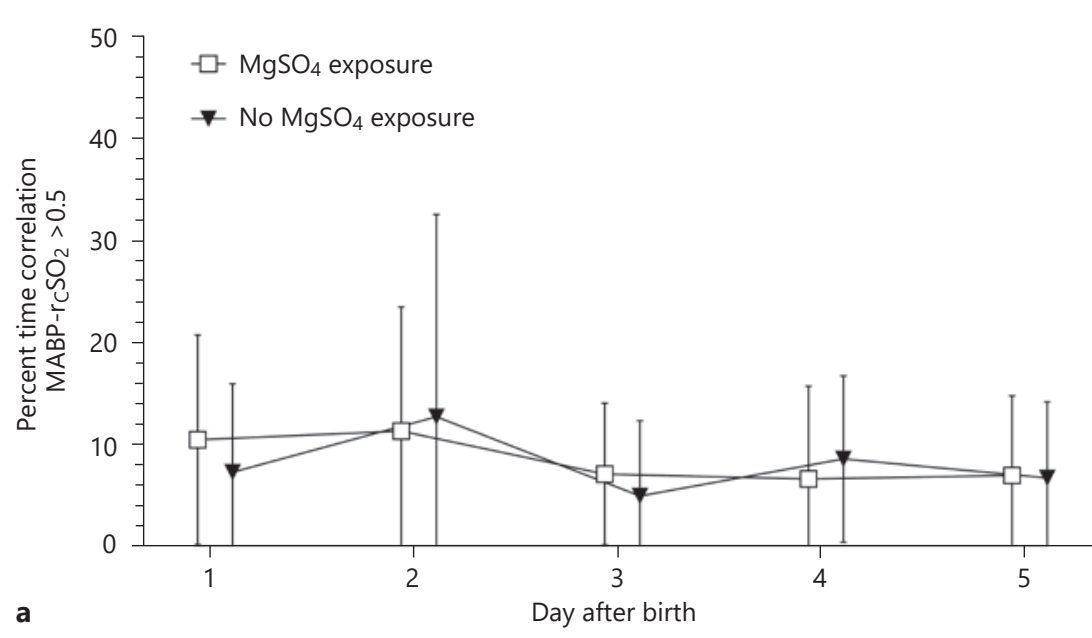

a

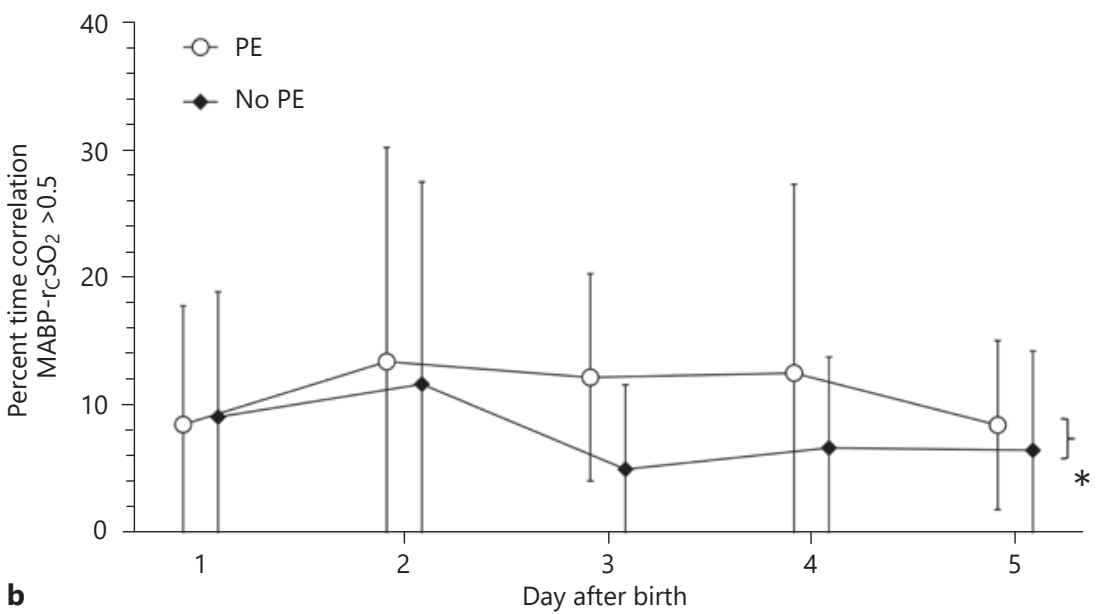

After forcing both $\mathrm{MgSO}_{4}$ and $\mathrm{PE}$ into a linear mixed model and adjusting the analyses for other confounders, the association between $\mathrm{PE}$ and CFTOE became insignificant, while the association between $\mathrm{MgSO}_{4}$ and cFTOE now reached statistical significance (Table 4). Additionally, GA and fetal brain sparing were significantly associated with lower postnatal cFTOE, with fetal brain sparing having the largest estimated effect. Moreover, the tendency towards a lower PSV following PE was lost. Other associations did not change. Of note, hsPDA significantly increased RI, which was particularly true on days 3 ( $p=$ $0.003)$ and $4(p=0.048)$. Effect dependency between PE and $\mathrm{MgSO}_{4}$ on our outcome variables was tested by the inclusion of an interaction term. However, as it had an insignificant effect on the regression coefficients (data not shown), it was removed from the models.
We found no significant correlations between cumulative dose and daily cFTOE in $\mathrm{MgSO}_{4}$-exposed infants.

\section{Cerebral Autoregulation}

CAR was determined in 53 infants. These infants required an arterial line for invasive MABP measurements, were of significantly lower GA and more often ventilated, and they more often developed an hsPDA, early-onset sepsis, and mild IVH than infants without an arterial line (all $p<0.05)$. Twenty-seven infants with invasive MABP and CAR measurements were exposed to $\mathrm{MgSO}_{4}$ and 8 were born following PE. In descriptive analyses, MABP was not different between infants with and without $\mathrm{MgSO}_{4}$ exposure or infants born after PE or non-PE pregnancy, but there was a trend towards a higher heart rate after $\mathrm{MgSO}_{4}$ exposure (day 4: $p=0.093$ ) and a signifi- 
Table 4. The association between $\mathrm{MgSO}_{4}$, preeclampsia (PE), and neonatal hemodynamic parameters during the first 5 days after birth analyzed using linear mixed-effect analyses with adjustment for confounders

\begin{tabular}{|c|c|c|c|c|}
\hline & B $[95 \%$ CI $]$ & SE & $p$ & VIF \\
\hline \multicolumn{5}{|l|}{ FTOE $(n=144)$} \\
\hline $\mathrm{MgSO}_{4}$ & $-0.026[-0.050$ to -0.002$]$ & 0.012 & $0.035^{* *}$ & 1.48 \\
\hline $\mathrm{PE}$ & $-0.005[-0.039$ to 0.028$]$ & 0.017 & 0.736 & 1.75 \\
\hline GA & $-0.008[-0.014$ to -0.002$]$ & 0.003 & $0.010^{* *}$ & 1.34 \\
\hline Antenatal steroids & $-0.020[-0.041$ to 0.002$]$ & 0.011 & $0.075^{*}$ & 1.20 \\
\hline Fetal brain sparing & $-0.039[-0.077$ to -0.002$]$ & 0.019 & $0.041^{* *}$ & 1.53 \\
\hline \multicolumn{5}{|l|}{$\mathrm{RI}(n=148)$} \\
\hline $\mathrm{MgSO}_{4}$ & $0.012[-0.014$ to 0.037$]$ & 0.013 & 0.372 & 1.28 \\
\hline $\mathrm{PE}$ & $-0.023[-0.054$ to 0.007$]$ & 0.015 & 0.133 & 1.16 \\
\hline GA & $0.001[-0.007$ to 0.008$]$ & 0.004 & 0.891 & 1.91 \\
\hline hsPDA & $0.054[0.022$ to 0.087$]$ & 0.016 & $0.001^{* *}$ & 1.60 \\
\hline PPROM & $-0.036[-0.065$ to -0.006$]$ & 0.015 & $0.017^{* *}$ & 1.11 \\
\hline \multicolumn{5}{|l|}{$\operatorname{PSV}(n=141)$} \\
\hline $\mathrm{MgSO}_{4}$ & $0.411[-4.174$ to 4.996$]$ & 2.307 & 0.859 & 1.34 \\
\hline $\mathrm{PE}$ & $-3.176[-9.846$ to 3.494$]$ & 3.363 & 0.347 & 1.79 \\
\hline GA & $0.661[-0.506$ to 1.828$]$ & 0.586 & 0.263 & 1.32 \\
\hline Fetal brain sparing & $-2.504[-9.899$ to 4.892$]$ & 3.728 & 0.503 & 1.64 \\
\hline \multicolumn{5}{|c|}{ Impaired CAR, $\%$ time $(n=51)$} \\
\hline $\mathrm{MgSO}_{4}$ & $-0.257[-3.741$ to 3.226$]$ & 1.723 & 0.882 & 1.40 \\
\hline $\mathrm{PE}$ & $1.453[-4.183$ to 7.088$]$ & 2.799 & 0.606 & 1.66 \\
\hline GA & $-0.335[-1.035$ to 0.366$]$ & 0.347 & 0.341 & 1.19 \\
\hline Fetal brain sparing & $6.071[0.959$ to 11.183$]$ & 2.543 & $0.021^{* *}$ & 1.42 \\
\hline
\end{tabular}

${ }^{*} p<0.1,{ }^{* *} p<0.05$. B, regression coefficient (effect estimate); CAR, cerebral autoregulation; CI, confidence interval; FTOE, fractional tissue oxygen extraction; GA, gestational age; hsPDA, hemodynamically significant (i.e., treatment-requiring) patent ductus arteriosus; PSV, peak systolic velocity; PPROM, prolonged premature rupture of membranes; RI, resistance index; SE, standard error; VIF, variance inflation factor.

cantly higher heart rate in infants born after PE (day 5: $p=0.017$; online suppl. Table 2).

$\mathrm{MgSO}_{4}$ did not affect CAR in either uni- or multivariate linear mixed model analysis (Tables 3, 4; Fig. 2). According to the univariate regression analysis, being born following PE was associated with an overall tendency towards impaired CAR within the first 5 days after birth but not on any postnatal day in particular (Table 3; Fig. 2). In the multivariate regression analysis, the tendency towards an association between PE and impaired CAR disappeared (Table 4). Instead, fetal brain sparing significantly increased the duration of impaired CAR.

\section{Discussion}

We investigated the effect of antenatal $\mathrm{MgSO}_{4}$ on neonatal cFTOE, CBF, and CAR following preterm birth, entangling it from concomitant PE-associated changes in fetal cerebral hemodynamics. We found that antenatal $\mathrm{MgSO}_{4}$ was associated with lower cFTOE after birth, but did not affect CAR or CBF, suggesting reduced oxygen consumption rather than increased oxygen supply. Moreover, the effect on cFTOE was independent from PE, which was itself associated with a lower cFTOE and a tendency towards lower PSV, suggesting increased oxygen supply from an increased CBF. In addition, PE tended to be associated with impaired CAR. Adjustment for confounders suggested that $\mathrm{PE}$-associated alterations in cerebral hemodynamics were mediated by fetal brain sparing.

The fact that $\mathrm{MgSO}_{4}$ independently lowers cFTOE by a reduction in regional oxygen consumption rather than increased oxygen supply has also been suggested by Stark et al. [15], who found that $\mathrm{MgSO}_{4}$ treatment for fetal neuroprotection was associated with lower $\mathrm{cFTOE}$ but not altered internal carotid blood flow on postnatal day 1 . We demonstrate that this effect endures until at least postnatal day 4 or 5, which was independent from cumulative 
dose but may reflect a prolonged elimination half-life of $\mathrm{MgSO}_{4}$ [16].

Reduced cerebral oxygen consumption following $\mathrm{MgSO}_{4}$ may result from decreased cerebral metabolism by blockade of excitatory glutamate NMDA receptors by magnesium [17]. Glutamate receptor blockade has been proposed as the major neuroprotective mechanism of $\mathrm{MgSO}_{4}$, reducing inflammation- and hypoxia-induced excitotoxicity [18]. An associated decrease in cerebral oxygen demands may further contribute to $\mathrm{MgSO}_{4}$-related neuroprotection, as it may reduce cerebral susceptibility to hypoxic insults. Previous studies relating high cFTOE levels to PVL may support this theory [19]. However, the difference in cFTOE was small (2-5\%), possibly even within the margin of error for detection of the device, and its clinical significance may be questioned. Moreover, in our study population, a trend existed towards more PVL following $\mathrm{MgSO}_{4}$, which may relate to more IVH in these infants.

Whether $\mathrm{MgSO}_{4}$ prevents or increases the risk of IVH is controversial $[3,20]$. While in our study mild IVH was more common following $\mathrm{MgSO}_{4}$, this may also be associated with lower GA. Although low cFTOE has ambiguously been associated with both an increased and reduced risk of IVH, potentially reflecting perfusional differences prior and following IVH, a lower cFTOE by $\mathrm{MgSO}_{4}$ was not associated with CBF $[21,22]$. In general, $\mathrm{MgSO}_{4}$ did not affect CBF. This was not supported by Shokry et al. [23], who reported a lower PSV, EDV, and mean flow velocity following $\mathrm{MgSO}_{4}$ but no difference in RI. Although they excluded infants born following PE, they suggested that a higher incidence of PDA in $\mathrm{MgSO}_{4}$-exposed infants may have confounded their results, but they did not adjust their analyses. Rantonen et al. [24], in contrast, also reported no effect by $\mathrm{MgSO}_{4}$ on pericallosal flow velocities and resistance. Instead, they demonstrated a decrease in cerebral perfusion pressure due to lower systolic blood pressure following $\mathrm{MgSO}_{4}$ exposure. They speculated that together with reduced cerebrovascular reactivity this may prevent IVH [24]. However, we did not find CAR to be altered by $\mathrm{MgSO}_{4}$, which is supported by experimental data [25]. $\mathrm{MgSO}_{4}$ is therefore unlikely to decrease or increase the risk of IVH by altering cerebrovascular reactivity, especially if it does not affect systemic blood pressure, as was the case in this study and large-scale meta-analyses [3]. Yet, an increased use of volume expansion and higher heart rates following $\mathrm{MgSO}_{4}$ have been reported [26], possibly reflecting the hypotensive potential of $\mathrm{MgSO}_{4}$. If profound, this could still cause cerebral perfusion pressures outside the autoregulatory range and cerebral hyp- oxia, in particular in those being very preterm or showing ongoing fetal brain sparing.

$\mathrm{PE}$ lowered cFTOE twice as much as $\mathrm{MgSO}_{4}$. Additionally, our data suggested PE-induced cerebral vasodilation and interference with CAR. These findings appeared to be mediated by fetal brain sparing, which literature supports [10,27]. Although brain sparing in fetal growth restriction has been associated with higher cerebral PSV through an increase in left-ventricular cardiac output, PSV may also decrease upon cardiac decompensation and continued cerebral vasodilation $[28,29]$. In support of this theory, growth-restricted neonates have demonstrated reduced left-ventricular output [30]. Moreover, continued cerebral vasodilation and cerebrovascular remodeling in chronic fetal hypoxia have been proposed to be responsible for impaired CAR after fetal brain sparing, although we were unable to confirm this due to sample size issues [31].

Although we expected a lower RI following PE due to cerebral luxury perfusion, we only observed a tendency towards lower RI on day 2 after birth [32]. This may relate to a weaker correlation with CBF due to unresponsiveness of RI if PSV and EDV are equally affected [32, 33]. Moreover, the upward slope in RI (and PSV) on days 3 and 4 suggested interference by PDA, which is known to increase RI, predominantly by affecting EDV but also PSV [32]. Indeed, PDA revealed to be a strong confounder on these days.

We recognize some limitations. First, data were retrospectively collected from routine clinical care. Although this allowed us to include a relatively large number of patients, it also reduced the completeness of data, in particular with respect to $\mathrm{CBF}$ and CAR. Moreover, we do not have information on the $\mathrm{pCO}_{2}$ at the time of hemodynamic assessment, which may have confounded our findings. Second, since CAR depends on invasive MABP measurements, which were only given in patients with an arterial line, this may also introduce a selection bias, as these infants were sicker. However, this should not have affected our conclusion, since infants born following PE, brain sparing, or $\mathrm{MgSO}_{4}$ did not require an arterial line more often than control infants. Third, CAR is a dynamic process and the presentation of 2-h data per day may not be fully representative. Future studies evaluating 24 -h measurements should confirm our findings. Fourth, we did not correct for multiple testing to reduce the chance of type 2 error as we consider this study exploratory. However, this may have also increased the chance of random false-positive findings. Finally, cerebral activity and metabolism were not assessed during the first days after birth 
and our conclusions regarding any relationship between $\mathrm{MgSO}_{4}$ and cerebral metabolism are merely based on the lack of effect on CBF in the face of an altered cFTOE.

In conclusion, $\mathrm{MgSO}_{4}$ exposure is associated with lower cFTOE within the first 5 days after preterm birth. This seems independent from $\mathrm{CBF}$ and may therefore more likely relate to reduced cerebral metabolism and oxygen consumption. Moreover, $\mathrm{MgSO}_{4}$ exposure at doses which do not induce neonatal hypotension does not alter CAR. Fetal brain sparing in concomitant $\mathrm{PE}$, on the contrary, lowers $\mathrm{cFTOE}$ through an increase in neonatal $\mathrm{CBF}$ and impairs CAR, possibly by cerebrovascular vasodilation and remodeling. Our data therefore suggest that $\mathrm{MgSO}_{4}$ is unlikely to affect cerebrovascular reactivity, but it may reduce cerebral susceptibility to hypoxia by reducing cerebral oxygen demands. Whether this is clinically relevant and outweighs a potential risk of cerebral hypoxia in infants with impaired CAR and/or $\mathrm{MgSO}_{4}$-induced hypotension needs to be investigated.

\section{Statement of Ethics}

This study was approved by the Medical Ethics Committee of the University Medical Center Groningen. Obtaining written informed consent was not required as this study was based on routine clinical care data. Parental objection to data use was checked for all participants. Presented data were anonymized.

\section{Disclosure Statement}

The authors have no conflicts of interest to declare.

\section{Funding Sources}

This study was part of the research program of the Research Institute of Behavioral and Cognitive Neurosciences (BCN), Graduate School of Medical Sciences, University of Groningen, participation in which is financially supported by the Junior Scientific Master Class of the University Medical Center Groningen, University of Groningen, The Netherlands. No grant or sponsor was involved in producing this article.

\section{Author Contributions}

Ms. A.E. Richter conceptualized the study, collected and analyzed the data, and drafted the first and final manuscript. Prof. S.A. Scherjon contributed to the study design and interpretation of the data and critically revised the manuscript for its intellectual content. Dr. R. Dikkers contributed to data collection and interpretation and critically revised the manuscript for its intellectual content. Prof. A.F. Bos contributed to the study design and interpretation of the data and critically revised the manuscript for its intellectual content. Dr. E.M.W. Kooi contributed to the study design and interpretation of the data and critically revised the manuscript for its intellectual content. All authors gave final approval of the version to be published and agree to be accountable for all aspects of the work.

\section{References}

1 Duley L, Gülmezoglu AM, Henderson-Smart DJ, Chou D. Magnesium sulphate and other anticonvulsants for women with pre-eclampsia. Cochrane Database Syst Rev. 2010 Nov; 2010(11):CD000025.

2 Bachnas MA, Akbar MI, Dachlan EG, Dekker $\mathrm{G}$. The role of magnesium sulfate $(\mathrm{MgSO} 4)$ in fetal neuroprotection. J Matern Fetal Neonatal Med. 2019 May;27:1-13.

3 Doyle LW, Crowther CA, Middleton P, Marret S, Rouse D. Magnesium sulphate for women at risk of preterm birth for neuroprotection of the fetus. Cochrane Database Syst Rev. 2009 Jan;(1):CD004661.

4 Burd I, Welling J, Kannan G, Johnston MV. Excitotoxicity as a common mechanism for fetal neuronal injury with hypoxia and intrauterine inflammation. Adv Pharmacol. 2016; 76:85-101.

5 Euser AG, Cipolla MJ. Magnesium sulfate for the treatment of eclampsia: a brief review. Stroke. 2009 Apr;40(4):1169-75.

6 Richter AE, Schat TE, Van Braeckel KN, Scherjon SA, Bos AF, Kooi EM. The effect of maternal antihypertensive drugs on the cerebral, renal and splanchnic tissue oxygen ex- traction of preterm neonates. Neonatology. 2016;110(3):163-71.

7 Souza AS, Amorim MM, Coêlho IC, Lima MM, Noronha Neto C, Figueroa JN. [Doppler of the umbilical and fetal middle cerebral arteries after magnesium sulfate in preeclampsia]. Rev Assoc Med Bras (1992). 2008 MayJun;54(3):232-7. Portuguese.

8 Dasgupta S, Ghosh D, Seal SL, Kamilya G, Karmakar M, Saha D. Randomized controlled study comparing effect of magnesium sulfate with placebo on fetal umbilical artery and middle cerebral artery blood flow in mild preeclampsia at $\geq 34$ weeks gestational age. J Obstet Gynaecol Res. 2012 May;38(5):763-71.

9 Imamoglu EY, Gursoy T, Karatekin G, Ovali F. Effects of antenatal magnesium sulfate treatment on cerebral blood flow velocities in preterm neonates. J Perinatol. 2014 Mar;34(3): 192-6.

10 Tanis JC, Boelen MR, Schmitz DM, Casarella $\mathrm{L}$, van der Laan ME, Bos AF, et al. Correlation between Doppler flow patterns in growth-restricted fetuses and neonatal circulation. Ultrasound Obstet Gynecol. 2016 Aug;48(2): 210-6.
11 Kooi EM, Verhagen EA, Elting JW, Czosnyka $\mathrm{M}$, Austin T, Wong FY, et al. Measuring cerebrovascular autoregulation in preterm infants using near-infrared spectroscopy: an overview of the literature. Expert Rev Neurother. 2017 Aug; 17(8):801-18.

12 Meijler G, Steggerda SJ. Transcranial Doppler Sonography in Neonates. In: Meijler G, Steggerda SJ: Neonatal Cranial Ultrasonography. 3rd ed. Berlin: Springer; 2019. p. 21957.

$13 \mathrm{Lu}$ JF, Nightingale CH. Magnesium sulfate in eclampsia and pre-eclampsia: pharmacokinetic principles. Clin Pharmacokinet. 2000 Apr;38(4):305-14.

14 Spinillo A, Gardella B, Bariselli S, Alfei A, Silini EM, Bello BD. Cerebroplacental Doppler ratio and placental histopathological features in pregnancies complicated by fetal growth restriction. J Perinat Med. 2014 May;42(3): 321-8.

15 Stark MJ, Hodyl NA, Andersen CC. Effects of antenatal magnesium sulfate treatment for neonatal neuro-protection on cerebral oxygen kinetics. Pediatr Res. 2015 Sep;78(3): 310-4.
Magnesium Sulfate, Preeclampsia, and Neonatal Cerebral Hemodynamics
Neonatology 2020;117:331-340 DOI: $10.1159 / 000507705$ 
16 Dangman BC, Rosen TS, James L. Magnesium levels in infants of mothers treated with MgSO4. Pediatr Res. 1977;11(4):415.

17 Lecuyer M, Rubio M, Chollat C, Lecointre M, Jégou S, Leroux P, et al. Experimental and clinical evidence of differential effects of magnesium sulfate on neuroprotection and angiogenesis in the fetal brain. Pharmacol Res Perspect. 2017 Aug;5(4):e00315.

18 Chollat C, Sentilhes L, Marret S. Fetal neuroprotection by magnesium sulfate: from translational research to clinical application. Front Neurol. 2018 Apr;9:247.

19 Verhagen EA, Keating P, ter Horst HJ, Martijn A, Bos AF. Cerebral oxygen saturation and extraction in preterm infants with transient periventricular echodensities. Pediatrics. 2009 Jul;124(1):294-301.

20 Mittendorf R, Dammann O, Lee KS. Brain lesions in newborns exposed to high-dose magnesium sulfate during preterm labor. J Perinatol. 2006 Jan;26(1):57-63.

21 Alderliesten T, Lemmers PM, Smarius JJ, van de Vosse, René E, Baerts W, van Bel F. Cerebral oxygenation, extraction, and autoregulation in very preterm infants who develop periintraventricular hemorrhage. J Pediatr. 2013 Apr;162(4):698-704.e2.

22 Verhagen EA, Ter Horst HJ, Keating P, Martijn A, Van Braeckel KN, Bos AF. Cerebral oxygenation in preterm infants with germinal matrix-intraventricular hemorrhages. Stroke. 2010 Dec;41(12):2901-7.
23 Shokry M, Elsedfy GO, Bassiouny MM, An$\min \mathrm{M}$, Abozid H. Effects of antenatal magnesium sulfate therapy on cerebral and systemic hemodynamics in preterm newborns. Acta Obstet Gynecol Scand. 2010 Jun;89(6):801-6.

24 Rantonen T, Kääpä P, Grönlund J, Ekblad U, Helenius H, Kero P, et al. Maternal magnesium sulfate treatment is associated with reduced brain-blood flow perfusion in preterm infants. Crit Care Med. 2001 Jul;29(7): 1460-5.

25 Schreurs MP, Cipolla MJ. Cerebrovascular dysfunction and blood-brain barrier permeability induced by oxidized LDL are prevented by apocynin and magnesium sulfate in female rats. J Cardiovasc Pharmacol. 2014 Jan; 63(1):33-9.

26 Paradisis M, Osborn DA, Evans N, Kluckow M. Randomized controlled trial of magnesium sulfate in women at risk of preterm delivery-neonatal cardiovascular effects. J Perinatol. 2012 Sep;32(9):665-70.

27 Polavarapu SR, Fitzgerald GD, Contag S, Hoffman SB. Utility of prenatal Doppler ultrasound to predict neonatal impaired cerebral autoregulation. J Perinatol. 2018 May; 38(5):474-81.
28 Figueroa-Diesel H, Hernandez-Andrade E, Acosta-Rojas R, Cabero L, Gratacos E. Doppler changes in the main fetal brain arteries at different stages of hemodynamic adaptation in severe intrauterine growth restriction. Ultrasound Obstet Gynecol. 2007 Sep;30(3): 297-302.

29 Mari G, Hanif F, Kruger M, Cosmi E, Santolaya-Forgas J, Treadwell MC. Middle cerebral artery peak systolic velocity: a new Doppler parameter in the assessment of growth-restricted fetuses. Ultrasound Obstet Gynecol. 2007 Mar;29(3):310-6.

30 Sehgal A, Doctor T, Menahem S. Cardiac function and arterial biophysical properties in small for gestational age infants: postnatal manifestations of fetal programming. J Pediatr. 2013 Nov; 163(5):1296-300.

31 Cohen E, Baerts W, van Bel F. Brain-Sparing in Intrauterine Growth Restriction: considerations for the Neonatologist. Neonatology. 2015;108(4):269-76.

32 Ecury-Goossen GM, Raets MM, Camfferman FA, Vos RH, van Rosmalen J, Reiss IK, et al. Resistive indices of cerebral arteries in very preterm infants: values throughout stay in the neonatal intensive care unit and impact of patent ductus arteriosus. Pediatr Radiol. 2016 Aug;46(9):1291-300.

33 Greisen G, Johansen K, Ellison PH, Fredriksen PS, Mali J, Friis-Hansen B. Cerebral blood flow in the newborn infant: comparison of Doppler ultrasound and 133xenon clearance. J Pediatr. 1984 Mar;104(3):411-8. 